\title{
USO DO FOGO EM PROPRIEDADES RURAIS DO CERRADO EM CAVALCANTE, GO
}

\section{FIRE USE IN CERRADO COUNTRY PROPERTIES IN CAVALCANTE, GO}

\author{
Daniel Xavier Lara ${ }^{1}$ Nilton César Fiedler ${ }^{2} \quad$ Marcelo Brilhante de Medeiros $^{3}$

\section{RESUMO}

O emprego do fogo é uma prática comum em regiões de menor tecnificação no meio rural. Essa prática requer uma série de cuidados para não causar desastres ambientais, como incêndios florestais. O fogo pode, acidentalmente, atingir cultivos, pastagens e benfeitorias. O objetivo deste trabalho foi avaliar os padrões de manejo e os impactos econômicos da utilização do fogo em propriedades rurais, na região da Chapada dos Veadeiros, no município de Cavalcante, estado de Goiás. A coleta de dados foi feita por meio de entrevistas, medições diretas em áreas atingidas, benfeitorias perdidas e avaliação dos custos. Foram entrevistados cinqüenta produtores rurais dos quais, parte utilizava o fogo como ferramenta de manejo agropecuário, e parte que, apesar de não fazerem uso do fogo, sofriam as conseqüências da utilização deste pelos vizinhos e pela falta de técnicas adequadas de prevenção a acidentes. A primeira etapa da coleta de dados foi realizada no ano de 2003. Foram levantadas informações quanto à área perdida com incêndios, prejuízos econômicos e investimentos em prevenção aos incêndios. No segundo levantamento, com foco na estação seca de 2004, feito com os mesmos 50 proprietários, comprovaram-se as informações já levantadas em 2003 e, assim, se pode promover um estudo comparativo entre as características de um período e outro. Concluiu-se que o uso do fogo trouxe elevados prejuízos econômicos tanto para aqueles agricultores que utilizavam o fogo como técnica agrícola quanto para aqueles que não o utilizavam. O desconhecimento das técnicas de substituição do uso do fogo era responsável pelo freqüente uso das queimadas controladas pelos produtores rurais. A falta de investimento em técnicas de prevenção tem levado toda a região a sofrer perdas enormes com os incêndios florestais constantes.

Palavras-chave: Incêndios florestais; causas de incêndios; perdas econômicas.

\section{ABSTRACT}

The use of fire as a land tool management is a common practice in the agricultural area. This practice requires a lot of care to avoid forest fires and uncontrollable fires. The uncontrollable fires can reach plantations, pastures and improvements. The objective of this work was to evaluate the fire management patterns and economic impacts of the fire management in the country areas in the region of Chapada dos Veadeiros, in the city of Cavalcante, Goiás. The data collection was made by means of direct interviews, burnt areas, improvements damages and costs evaluation. Fifty agricultural producers used the fire as a tool of farming handling. The first stage of the data collection was carried out during 2003. Information on the size of burnt area, damages and investments in wildfire prevention was collected. The second survey, mode with the same 50 land owners, was carried out in 2004 dry station. The data of 2003 and 2004 was compared. Results showed that the use of fire, in such a place, causes damages for those land owners who use the fire as a land management tool and for land owners who do not use it. The lack of prevention activities and fire control approaches are the main causes of uncrontrolled burnts in Chapada dos Veadeiros.

Keywords: Forest fire; fire causes; economic impacts.

\section{INTRODUÇÃO}

O bioma Cerrado, localizado no Planalto Central do Brasil, cobre cerca de 23\% do território brasileiro, aproximadamente dois milhões de quilômetros quadrados (Ribeiro e Walter, 1998). A vegetação é representada pelas formas fisionômicas: cerrado sensu stricto, cerradão, campo sujo, campo limpo, matas de galeria, veredas (Eiten,1994; Ribeiro e Walter,1998). Por ser uma das principais fronteiras agrícolas do País, atualmente, esse bioma se encontra bastante ameaçado. Nos últimos 35 anos, a agricultura tecnificada se

1. Engenheiro Florestal, Mestre em Ciências Florestais pela Universidade de Brasília, Caixa Postal 04357, CEP 70910-900, Brasília (DF). daniellara@pop.com.br

2. Engenheiro Florestal, Dr., Professor Adjunto do Departamento de Engenharia Florestal, Universidade Federal do Espírito Santo, CEP 29550-000, Jerônimo Monteiro (ES). fiedler@cca.ufes.br

3. Engenheiro Florestal, Dr., Pesquisador CENARGEN/EMBRAPA, Av. W5 Norte, Final, CEP 70910-900, Brasília (DF). medeiros@cenargen.embrapa.br

Recebido para publicação em 26/04/2005 e aceito em 8/09/2006. 
estende sobre o domínio dos cerrados que está sendo desmatado para dar origem a grandes maciços agrícolas e pecuários, causando fortes impactos ambientais ao ecossistema.

O fogo no Cerrado é um fenômeno antigo, evidenciado pela existência de amostras de carvão datados entre 27100 a 41700 anos antes do presente com o homem primitivo que utilizava o fogo para caçar, guerrear e preparar o solo (Vicentini, 1993). Ele se caracteriza como um dos fatores determinantes do tipo de vegetação savânica, sendo considerado como fator de diversidade fisionômica (Sato, 2003). Porém, atualmente a principal causa dos incêndios florestais na região é o uso do fogo para limpeza agrícola ou pastoril na forma de queimada controlada. No entanto, o negligenciamento de ações básicas de controle tem acarretado perdas imensas tanto do ponto de vista ambiental quanto econômicas (Coutinho, 1990).

A queimada controlada é considerada como método barato para preparar a terra para o plantio de culturas e para a renovação de pastagens, pois além de eliminar a vegetação da área, as árvores derrubadas e queimadas produzem cinzas ricas em nutrientes que fertilizam o solo e, no curto prazo, aumentam sua produtividade. O fogo é usado também para estimular o crescimento de gramíneas forrageiras de pastagens e matar as plantas invasoras lenhosas que invadem essas pastagens. Sem o fogo, os proprietários rurais teriam, certamente, de investir na compra de máquinas para remover as árvores caídas e despender tempo roçando as ervas daninhas que invadem as pastagens (Nepstad, Moreira e Alencar, 1999).

Paradoxalmente, o fogo acarreta prejuízos para os fazendeiros e agricultores queimando áreas indesejáveis. Esse risco do fogo sem controle desestimula os proprietários a investirem em suas propriedades, perpetuando o domínio da pecuária e da agricultura extensivas e queima em detrimento do estabelecimento de sistemas agrícolas, pecuários e silviculturais mais adequados do ponto de vista ambiental e econômico e do uso de técnicas que substituam o uso do fogo. A perda de pastagens pelas queimadas acidentais é um dos principais custos econômicos privados que atingem os proprietários rurais. A elevada inflamabilidade das áreas antropizadas, em épocas de seca, afeta os fazendeiros na medida em que uma pastagem queimada acidentalmente obriga o proprietário a buscar uma nova área de pastagem para onde possa transferir seu rebanho bovino. O tempo de uso desse pasto substituto chega, em média, a três meses, tempo necessário para que o capim se recupere da ação do fogo (Alencar et al., 1997; Nepstad, Moreira e Alencar, 1999).

Estudo realizado por Motta et al., (2002) sobre o custo econômico do fogo na Amazônia estimou, em consequiência do fogo acidental nos pastos, a destruição de cercas, a perda de carbono das florestas e os impactos na saúde humana. As previsões desse estudo mais conservadoras indicaram custos médios anuais de US\$ 102 milhões ou 0,2\% do PIB total da região para o período 1996-1999, dependendo de como se valora o carbono liberado.

Outros custos diretos significativos para o proprietário estão relacionados com a destruição de benfeitorias, plantações e recursos madeireiros. No caso da queima de cercas, o prejuízo pode variar da destruição completa das estacas e arame pelo fogo, ao aquecimento do arame, expondo-o a uma rápida deterioração pela ferrugem. Os danos aos cultivos perenes e árvores frutíferas pelo fogo acidental causam também grandes perdas decorrentes do alto investimento necessário para estabelecer e manter essas culturas. As espécies madeireiras de valor comercial também são afetadas pelos incêndios florestais, podendo levar a perdas econômicas significativas, sobretudo quando a área queimada é uma floresta não-explorada (Motta et al., 2002).

No meio rural, o principal objetivo das atividades de prevenção é evitar a ocorrência de incêndios florestais (Fiedler et al., 2000; Medeiros, 2002).

A educação visando à prevenção a incêndios deve ter participação de entidades oficiais e particulares, visando à conscientização da população sobre técnicas de prevenção e combate aos incêndios. Pequenos proprietários geralmente não possuem condições para o desenvolvimento de trabalhos isolados de proteção, em decorrência das limitações financeiras, localizando o fogo em seu início e desencadeando um processo de controle, mesmo dentro dos limites de suas propriedades, evitando que se alastre para áreas circunvizinhas. Associações particulares, englobando organizações de poderio econômico, pequenos proprietários e entidades oficiais, reunindo-se em ação cooperativa, têm condições de realizar melhor essa tarefa, durante a prevenção, localização e extinção dos incêndios em seu início(Medeiros, 2002). 
Esta pesquisa teve como objetivo avaliar as causas e os impactos econômicos do uso do fogo em propriedades rurais no Cerrado, no município de Cavalcante, estado de Goiás.

\section{MATERIAL E MÉTODOS}

Esta pesquisa foi realizada nos anos de 2003 e 2004 em cinqüenta propriedades rurais, representando cerca de 5\% dentre as 1.012 propriedades existentes no município de Cavalcante, estado de Goiás. O Município localiza-se na mesoregião do norte goiano e na macroregião denominada Chapada dos Veadeiros. O município se estende até o lado norte do Parque Nacional da Chapada dos Veadeiros, com área territorial de 694.400 ha. A área total das propriedades estudadas foi de 76.155,45 ha, ou $11 \%$ da área da região. Destes, 34\% são de pequenas propriedades, com área variando de 0-100 hectares, $46 \%$ de médias propriedades, com área de 101-500 hectares e 20\% de grandes propriedades, com áreas maiores que 500 hectares.

O público-alvo da pesquisa foi os produtores rurais do município que utilizavam o fogo como técnica de limpeza de pastagens e aqueles que, apesar de não utilizarem o fogo, sofriam as conseqüências da utilização deste pelos vizinhos. A avaliação foi realizada com observação direta intensiva e aplicação de entrevista para levantamento das informações. Estas foram aplicadas em forma de questionário in loco para obter dados sobre os padrões da utilização do fogo pelos proprietários rurais da região de Cavalcante, estado de Goiás. O tipo de entrevista utilizada foi a estruturada ou padronizada, que possui, em ordem de importância, as questões sobre as características da utilização do fogo como técnicas de manejo pelos proprietários rurais, os investimentos feitos para prevenção, os acidentes decorrentes da utilização de fogo e a presença de órgãos federais, estaduais ou organizações não-governamentais de assistência técnica e extensão para orientação sobre o tema.

Para o cálculo das perdas econômicas dos proprietários com os incêndios florestais, foram mensuradas as áreas queimadas nas propriedades e as benfeitorias, pastagens e culturas perdidas.

No caso de pastagens e culturas, calculou-se de acordo com a Equação 1:

$\mathrm{CPP}=\mathrm{Va}+\mathrm{CFC}$

Em que: CPP = custo de perdas com pastagens por hectare; Va = valor médio do aluguel de pastagem na região, por hectare, durante quatro meses (tempo necessário para recuperação); CFc = custo para formação da cultura ((diárias trabalhadas x valor da diária) + (número de horas de trator x valor da hora de trator) + custo da adubação/ha).

Nas perdas com cercas, calculou-se o preço para reestabelecer uma cerca de acordo com a equação 2:

$\mathrm{Cc}=(\mathrm{Cem} * \mathrm{Q})+\mathrm{Ca} * \mathrm{Q}+\mathrm{Cmo}+\mathrm{CT}$

Em que: $\mathrm{Cc}=$ Custo com cercas; $\mathrm{Cem}=$ custo das estacas e mourões; $\mathrm{Q}=$ quantidade utilizada; $\mathrm{Ca}=$ custo de arame; $\mathrm{Cmo}$ = custo de mão de obra; $\mathrm{CT}$ = custo de transporte de material e pessoal.

A esses cálculos, foram somados as perdas com animais (calculados pelo preço de venda de um animal nas mesmas características do que foi perdido) e perdas de casas, currais ou qualquer material existente na propriedade, calculado com base no valor de mercado regional. Todos esses valores foram somados aos valores anteriormente descritos, e estes calculados conforme preços de mercado, na região, da época de sua aquisição.

No caso do custo para estabelecimento de uma cerca na região, o valor foi calculado da seguinte forma:

Em $1 \mathrm{~km}$ de cerca eram gastos:

- 8 rolos de arame liso de 500 metros $=\mathrm{R} \$ 880,00$ - preço unitário $\mathrm{R} \$ 110,00$;

-100 estacas $=\mathrm{R} \$ 1.000,00-$ preço unitário 10,00;

- 10 mourões $=\mathrm{R} \$ 400,00$ - preço unitário 40,00;

-8 esticadores $=\mathrm{R} \$ 20,00$ - preço unitário 2,50;

- mão-de-obra $=\mathrm{R} \$ 600,00$;

- transporte do material até a propriedade $=\mathrm{R} \$ 100,00$.

Para o estabelecimento de cerca em um km eram gastos: $\mathrm{R} \$ 3.000,00$. 
Para o aluguel de um hectare de pasto na região gastava-se na época, R\$ 35,00/hectare/mês, sendo que o tempo de recuperação média dos pastos queimados era de 4 meses. Assim, o valor final do aluguel de pasto para a região foi de $\mathrm{R} \$ 175,00$ por hectare.

Para o cálculo de benfeitorias queimadas, como casas e currais, o valor do prejuízo foi aquele investido inicialmente no estabelecimento deste, segundo o valor de mercado da região.

Os aceiros eram a única técnica de prevenção a acidentes com fogo utilizado pelos produtores rurais do município de Cavalcante/GO. Tais aceiros possuíam em média 5 metros de largura, e usualmente eram confeccionados mecanicamente por tratores, ou manualmente por capina.

O custo estimado para formação de aceiros nas propriedades localizadas no município de Cavalcante/GO foi assim calculado:

- para a formação por capina - manualmente, 15 reais a diária x 10 dias de trabalho (150,00 reais/km) ou 15 reais em diárias por 15 dias de trabalho (225,00 reais/ha).

- para a formação pelo uso de trator, mecânico (56,00 reais/hora/km ou 32,00 reais/hora/ha).

\section{RESULTADOS E DISCUSSÃO}

De acordo com as informações levantadas com os cinqüenta produtores rurais do município de Cavalcante, enquanto se investiu um total anual médio de $\mathrm{R}$ \$ 16.666,00 ou $\mathrm{R}$ \$ 0,22/ha em ações preventivas, perdeu-se em incêndios florestais R \$ 468.464,00/ano ou R \$ 6,15/ha/ano.

Do total perdido anualmente em incêndios, $48 \%$ ou cerca de R\$224.730,00, foram perdidos pelos proprietários que realizavam queima controlada para qualquer ação. Estes foram prejudicados pelos seus vizinhos que realizavam queimadas de forma inadequada e pela ausência de técnicas de prevenção a incêndios. Outros 33\% (R \$ 153.952,00) foram perdidos pelos proprietários que utilizavam o fogo com a freqüência anual de queima. Aproximadamente 16\% (R\$ 74.137,50) pelos proprietários com freqüência bianual e 3\%, ou R \$ 15.645,00, com freqüência superior a três anos (Figura 1). Perdas econômicas elevadas decorrentes de queimadas descontroladas têm sido observadas em áreas rurais da Amazônia (Nepstad et al., 1999).

A Figura 1 mostra, também, que entre os proprietários que utilizavam o fogo, os que o faziam em freqüência trianual ou superior tiveram, em reais, as menores perdas, até em comparação aos que não utilizavam o fogo. Isso ocorreu provavelmente pelo fato de que essas propriedades seriam circunvizinhas àquelas que não utilizavam o fogo. Assim houve poucos incêndios advindos da utilização do fogo pelos vizinhos. A maioria dos entrevistados, que não utilizavam o fogo, possuíam vizinhos que utilizavam o fogo com freqüências anuais e bianuais.

As áreas perdidas com incêndios tendem a ser maiores nas regiões do município onde existem mais produtores que utilizam o fogo. A Figura 2 mostra que, tanto em 2003 como em 2004, as áreas perdidas por incêndios florestais, entre os proprietários que utilizavam a queimada, foram maiores nas propriedades com menores freqüências de queima. Os produtores que utilizavam o fogo anualmente e bianualmente perderam, em média, anualmente, com os incêndios florestais, 748,4 e 423,5 hectares respectivamente, ou seja 1\% e 0,55\% da área total. A utilização de queimadas em mutirão e/ou o aviso dos vizinhos são práticas simples que têm sido eficientes para a redução de incêndios florestais e queimadas descontroladas em comunidades rurais na Amazônia (Nepstad et al., 1999). Práticas similares também podem ser empregadas na região do Cerrado com custos reduzidos de treinamento.

A Figura 2 mostra também que, onde os intervalos de queima eram maiores, as áreas queimadas por incêndios foram menores. Os produtores que faziam queima controlada de três a mais anos de intervalo tiveram perdas , em média, anualmente de 122,8 hectares (0,16\% da área total). 


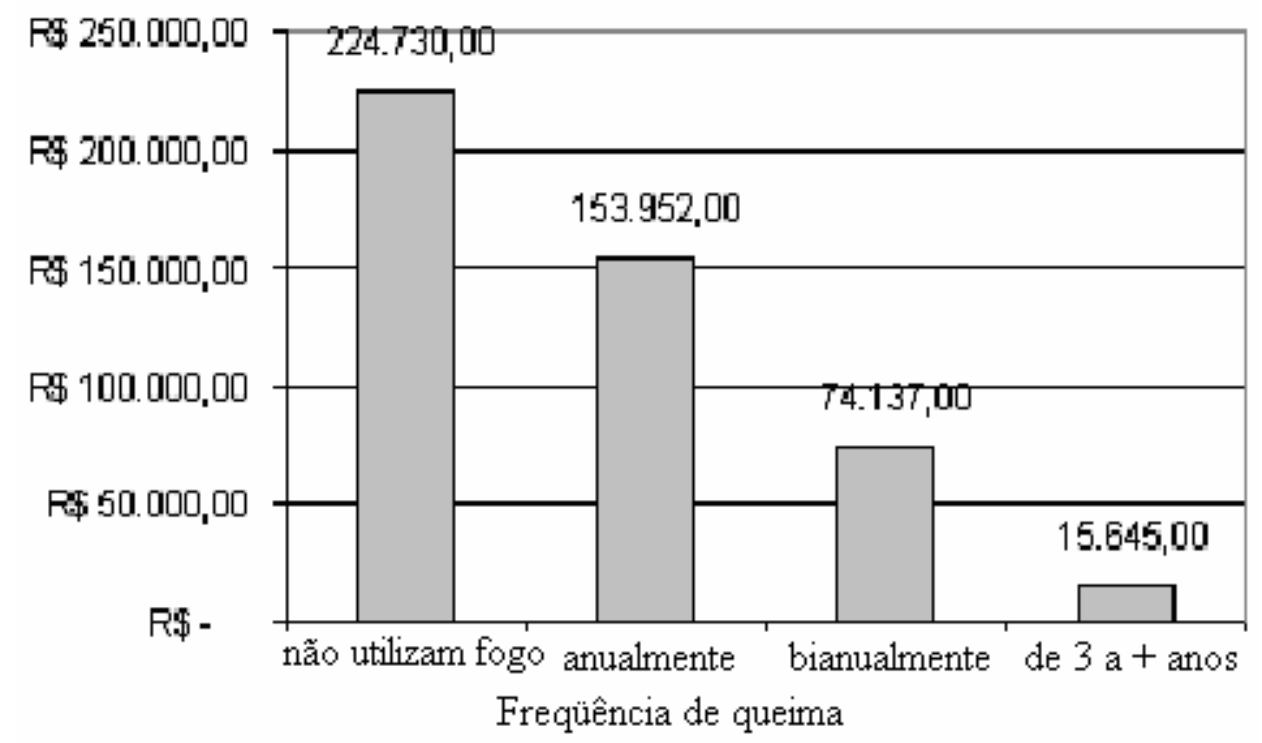

FIGURA 1: Freqüência de queima controlada e perdas econômicas dos proprietários rurais do município de Cavalcante (GO) com incêndios florestais.

FIGURE 1: Fire frequency and economic costs to land owners of Cavalcante (GO) with forest fires.

O diferencial entre os dois anos de análise está no total perdido em área dos produtores que não utilizavam o fogo. Enquanto em 2003 o número foi de 1134,3 ha, o que representa 1,5\% da área total, em 2004 esse valor subiu para 2400 ha (3,15\% da área total).

Esse fato ocorreu em função de que o ano de 2003 foi um ano de queima para aqueles produtores que o faziam com as freqüências de 2 em 2 anos e de 3 a mais anos. Nessa época, esses produtores que utilizavam o fogo e seus vizinhos que não o faziam investiram mais na manutenção e formação de aceiros, impedindo, assim, muitos incêndios. Em 2004, por não ter sido um ano de realização de queimadas por esses produtores, muitos aceiros não tiveram a devida manutenção, nem foram feitos outros, tanto pelos proprietários que utilizavam quanto àqueles que não utilizavam o fogo. Assim, quando houve algum incêndio florestal, os incêndios acabaram acontecendo e atingindo também aqueles que não faziam uso do fogo. Dessa forma, nota-se a extrema importância da manutenção anual dos aceiros por todos os proprietários rurais do Município.

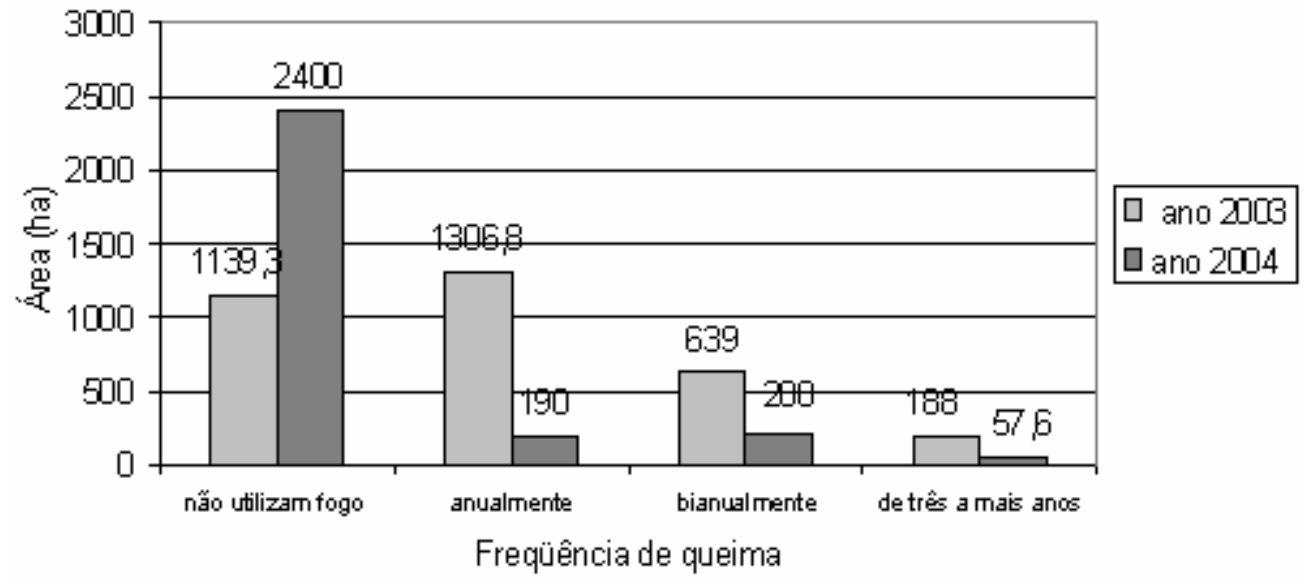

FIGURA 2: Freqüência de queima pelos produtores rurais e área perdida com incêndios no município de Cavalcante, GO.

FIGURE 2: Burnt frequency and burnt area of land owners at Cavalcante, GO.

Essa periodicidade de queima curta, associada à falta de investimento na prevenção de incêndios, é uma das principais causas dos prejuízos constatados na região. A Figura 3 mostra que, dos 23 proprietários que não utilizavam o fogo, $52 \%$ não faziam qualquer investimento e $48 \%$ investiam em ações preventivas 
um total médio de R\$ 4.155,00 por ano em manutenção de aceiros, ou R\$ 0,06/ha/ano. Dos proprietários que utilizavam o fogo, $30 \%$ não faziam investimento algum em prevenção. Os $70 \%$ que faziam, investiam R \$ 0,18/ha/ano ou R \$ 12.511,00.

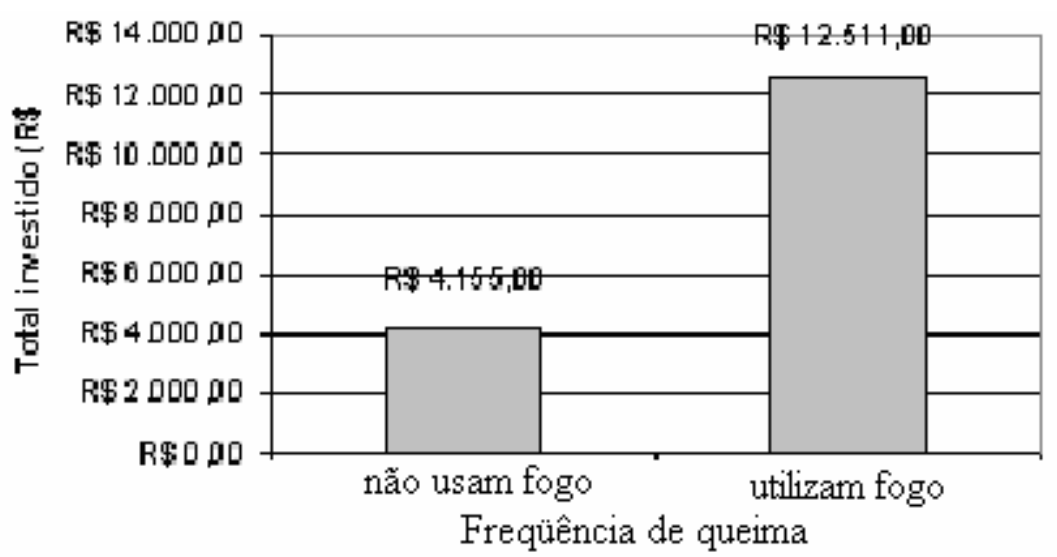

FIGURA 3: Total investido pelos proprietários, anualmente, em prevenção, e uso de queima, em Cavalcante, GO.

FIGURE 3: Land owners’ total investment, annualy and burnt frequency at Cavalcante, GO.

Outro dado importante é que a única forma de prevenção utilizada pelos produtores rurais foi a construção e manutenção de aceiros, demonstrando que durante o ato da queima nenhum dos produtores entrevistados conhecia ou utilizava técnica, ferramentas, máquinas e equipamentos seguros, como abafadores, bombas-costais, caminhão-pipa, fogo contra fogo, queima em períodos apropriados e mutirões de queima.

O total perdido anualmente com cercas de arame foi de $\mathrm{R} \$ 83.721,50$, com média de 28,5 quilômetros de cerca perdida por ano.

Com pastagens formadas ou naturais o valor perdido foi de R\$ 321.557,50/ano. As perdas com benfeitorias foram de $\mathrm{R}$ \$21.880,00/ano (casas, currais, materiais para construção, cabeças de gado, acessos construídos). As perdas com culturas foram de R\$25.000,00/ano ( Figura 4). As perdas de áreas nativas de cerrado e matas de galeria não foram quantificadas nesta pesquisa.

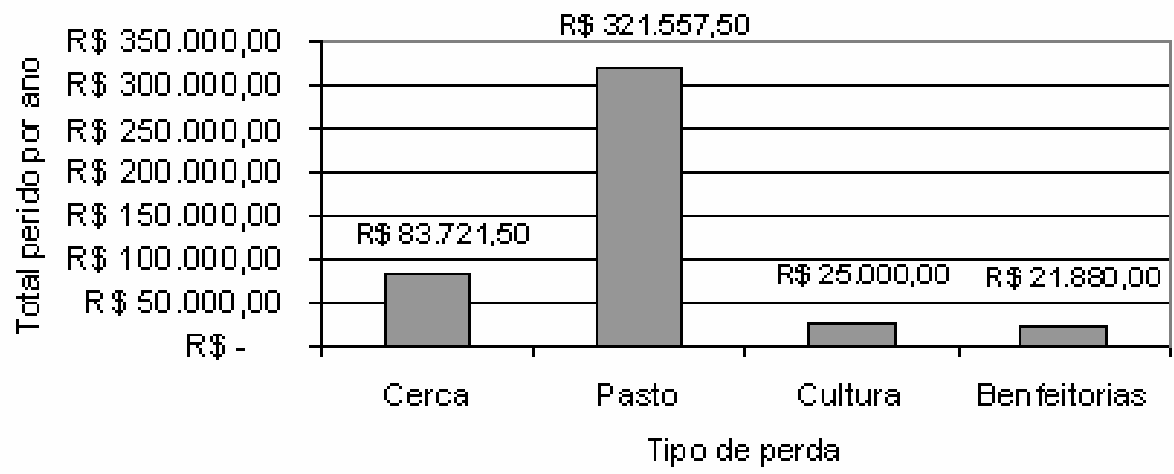

FIGURA 4: Perdas econômicas de propriedades rurais com incêndios florestais no município de Cavalcante, GO.

FIGURE 4: Economic costs of land owners with forest fires in Cavalcante, GO.

O valor mensurado das perdas (Figura 4) indica que de todos os prejuízos causados por incêndios, a queima de pastagens foi a maior (71\% dos prejuízos).

Os resultados mostram a falta de investimentos em técnicas de manejo, como pastejo rotacionado intensivo com adubação e utilização de espécies forrageiras diferentes para obtenção de maior quantidade de forragem. Sem apoio técnico para utilização do fogo ou alternativas à utilização, ações preventivas e formação de mutirões de queima controlada, os incêndios florestais na região demandam custos elevados aos proprietários rurais que não são mensurados e avaliados estes. 


\section{CONCLUSÕES}

As perdas sofridas com a falta de técnicas, na utilização do fogo e na prevenção a incêndios, foram consideradas grandes. Em 2003 e 2004 não apenas os proprietários que utilizaram o fogo tiveram prejuízos. Aqueles que não utilizavam tiveram um prejuízo total, de $\mathrm{R}$ \$3,00/ha/ano. Os que utilizavam com freqüência anual, R\$ 2,00/ha/ano, bianual R\$ 1,00/ha/ano e de três a mais anos R\$ 0,20/ha/ano. Esses números demonstram que não apenas os que utilizam o fogo têm prejuízos com acidentes, mas também os que não o utilizam. Isso ocorre em função da falta de investimento na prevenção de incêndios, tanto por quem utiliza o fogo como também quem não o faz.

O total investido em prevenção, em 2003 e 2004, pelos proprietários entrevistados foi de R\$ 0,22/ha/ano. Os proprietários que não utilizam o fogo investiram cerca de R $0,06 / \mathrm{ha} /$ ano, os que fazem uso de queimadas controladas investiram R \$ 1,43/ha/ano.

Das perdas econômicas, a que mais se destacou foi os prejuízos com a queima de pastos formados, anualmente de $\mathrm{R} \$ 321.557,50$. Outra perda significativa foi a queima das cercas com acidentes que gerou um

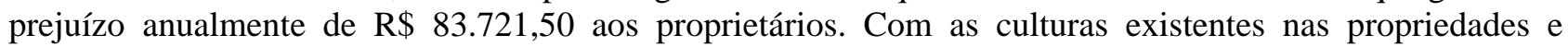
benfeitorias ocorreram perdas de $\mathrm{R} \$ 25.000,00 /$ ano e 21.880,00/ano respectivamente.

O fato de utilizar ou não o fogo não foi o principal agente causador dos prejuízos com os incêndios florestais. A inexistência de técnicas de prevenção e pré-supressão de incêndios aliada à falta de técnica na utilização de queimadas controladas foram os responsáveis pelos incêndios ocorridos no período analisado.

\section{REFERÊNCIAS BIBLIOGRAFICAS}

ALENCAR, A., NEPSTAD, D., SILVA, E., BROWN, F., LEFEBVRE, P., MENDOSA, E., ALMEIDA, D., CARVALHO Jr. O uso do fogo na Amazônia: estudos de caso ao longo do arco de desmatamento. Brasília: World Bank Report, 1997.

COUTINHO, L. M. Fire in ecology of Brazilian Cerrado. In: Goldammer, J. G. (ed.). Fire in the tropical biotaecossystem processes and global challenges. Berlin: Springer, 1990.

(Ecological Studies, Vol. 8A)

CRUZ, C. D. Programa Genes: versão windows, aplicativo computacional em genética e estatística. Viçosa: UFV, 2001. 648p.: il.

EITEN, G. Vegetação do cerrado. In: PINTO, M. N. (ed.) Cerrado. Brasília: SEMATEC, 1994. p. 17-76.

FIEDLER, N.C.; SILVA, J.C.; SANTIAGO, J.; MEDEIROS, M.B. Combate aos incêndios florestais. Revista Comunicações Técnicas Florestais, Brasília,v. 1, n. 2, p. 1-36, 2000.

MARCOUliDES, G. A.; HERSHBERGER, Scott L. Multivariate statistical methods: a first course. Mahwah : Lawrence Erlbaum Associates, 1997. 344 p.

MEDEIROS, M. B. Manejo do fogo em unidades de conservação do cerrado. Boletim do Herbário Ezechias Paulo Heringer, v. 10, p. 76-89, 2002.

MOTTA, R. S. da, MENDONÇA, M. J. C., NEPSTAD, D., DIAZ, M. del C. V., ALENCAR, A., GOMES, J. C., ORTIZ, R. A. O custo econômico do fogo na Amazônia. Rio de Janeiro : IPEA, 2002. 42p. (Texto para discussão ; n. 912)

NEPSTAD, D. C. A.; MOREIRA A. A.; ALENCAR. Flames in the rain forest: origins, impacts and alternatives to amazonian fires. Brasília: UnB, 1999.

RIBEIRO, J. F.; WALTER, B. M. T. Fitofisionomias do bioma Cerrado. In: SANO, S. M. ; ALMEIDA, S. P. de (eds.) Cerrado: ambiente e flora. Planaltina : Embrapa-CPAC, 1998. p.89-168.

SATO, M. N. Efeito a longo prazo de queimadas prescritas na estrutura da comunidade de lenhosas da vegetação do Cerrado sensu stricto. 2003. Dissertação (mestrado) - Universidade de Brasília, Brasília, 2003.

SOARES, R. V. Prevenção e controle de incêndios florestais. Curitiba : FUPEF, 1979. 72p.

VICENTINI, K. R. C. F. Análise palinológica de uma vereda em Cromínia-GO. 1993. Dissertação (Mestrado) Universidade de Brasília, Brasília, 1993. 